\title{
PENGARUH KUALITAS PELAYANAN (DISTRIBUTIVE JUSTICE, PROCEDURAL JUSTICE, INTERNATIONAL JUSTICE) TERHADAP KEPUASAN NASABAH
}

\author{
Sarida Sirait ${ }^{1)}$, Calen ${ }^{2)}$ \\ ${ }^{1}$ Komputerisasi Akuntansi, Politeknik Bisnis Indonesia \\ email: saridasrt@gmail.com \\ ${ }^{2}$ Manajemen, Sekolah Tinggi Akuntansi Dan Manajemen Indonesia \\ email: calen.chan88@gmail.com
}

\begin{abstract}
Technological developments are so fast and fast that all banks are increasingly trying to provide excellent service to customers who are the spearhead of the banking business. The high competition in the banking business and the heterogeneous condition of customers make the management have to make efforts to improve services. the inability of banks to deal with customer complaints makes customers dissatisfied and shifting. The large costs associated with service recovery have prevented the banking sector from responding quickly to various customer complaints or customers. The purpose of this study is to determine the extent to which service recovery can improve banking services. The independent variable (independent) in this study is service quality $(X)$, namely the application of service recovery strategies consisting of distributive justice, procedural justice, and interactional justice. Meanwhile, the determining variable (dependent) is customer satisfaction (Y) at Bank BRI Pasar Horas Unit. The analytical technique used in this study is linear regression to see how much influence the variable $X$ has on $Y$. The results of data processing using SPSS are that $X$ has a significant positive effect on $Y$ with a significance value of 0.00 and a coefficient of determination ( $R$ Square) of 0.772 . The magnitude of the coefficient of determination of 0.772 is equal to $77.2 \%$, this figure implies that quality affects customer satisfaction by $77.2 \%$
\end{abstract}

Keywords: service quality, customer satisfaction, service recovery

\section{PENDAHULUAN}

Sistem perbankan sangat berpengaruh terhadap pertumbuhan masyarakat karena persaingan semakin ketat antar bank satu dengan bank lainnya [1]. Hal ini mendorong setiap bank untuk memberikan pelayanan prima kepada nasabah yang sudah mempercayai bank tersebut, masing-masing dari bank yang ada di Indonesia mempunyai program yang terus diperbarui dan tidak ada bank yang tidak memperbaharui programnya [2]. Adapun jenis program tersebut ada yang berbentuk layanan-layanan baru yang akan membuat nasabah semakin mudah untuk melakukan setiap transaksinya [3]. Dari semua program itu dimaksudkan untuk membuat masyarakat semakin tertarik untuk menjadi nasabah baru di bank tersebut, dan juga untuk dapat mempertahankan agar nasabah yang sudah lama tidak akan berpaling dan memilih bank lain.Ada banyak usaha yang dapat dilakukan oleh bank agar mampu bersaing terhadap para pesaingnya yaitu bank lainnya, salah satu usaha yang dapat dilakukan oleh bank yaitu dengan mengikuti setiap revolusi industri dan teknologi, khususnya bagian informasi dan komunikasi. Adapun manfaat dari penerapan teknologi yang telah dirasakan oleh setiap nasabah selain automatic teller machine (ATM) adalah 
credit card, debit card, phone banking, internet banking dan mobile banking [4]. Dengan penerapan teknologi yang akan dilakukan pihak bank maka diharapkan nasabah dapat merasakan kemudahan dalam menggunakan jasa perbankan yang disediakan oleh pihak bank, kebebasan bertindak dalam waktu pelayanan, kecepatan dan ketepatan, keamanan data nasabah dan keanekaragaman jenis layanan [5]. Setiap nasabah yang merupakan konsumen pemakai dari produk yang disediakan didalam setiap bank mempunyai kebebasan dalam memilih sesuai dengan kebutuhan yang sedang dibutuhkan oleh nasabah tersebut. Dari semua jenis produk yang hampir sejenis akan ditawarkan oleh setiap bank, maka dari itu akan mendorong setiap nasabah untuk lebih memperhatikan bagian kualitas layanan dan kepuasan yang diperoleh nasabah dari setiap penggunaan produk yang disediakan oleh bank tersebut. Kualitas pelayanan dan kepuasan nasabah ini adalah sesuatu yang harus dipahami oleh setiap bank agar dapat mencapai tujuan dari organisasinya. Didalam setiap bagian organisasi jasa akan berusaha semaksimal mungkin agar tidak terjadi service failure yang bertujuan untuk menghemat setiap biaya yang harus dikeluarkan untuk memperbaiki service failure tersebut [6] [7]. Setiap bank lebih menginginkan layanan yang bebas dari kesalahan daripada perbaikan yang sempurna. Namun diberbagai keadaan yang ada menyebabkan disetiap bagian organisasi tidak akan biasa mengelak dari terjadinya service failure. Maka dari itu organisasi harus dapat mempertahankan setiap nasabahnya dan jangan sampai nasabah dari bank tersebut akan berpaling serta lebih memilih bank lain. Sekalipun bank telah berusaha semaksimal mungkin untuk melakukan yang terbaik dalam rangka memenuhi setiap kebutuhan dan keinginan dari para nasabahnya tetapi tetap saja bank tidak dapat menutup kemungkinan bahwa kegagalan jasa atau yang lebih sering disebut service failure tetap saja akan dapat terjadi dikemudian hari. Adapun kunci dari kesuksesan setiap bank adalah harus bersikap proaktif dalam meminimumkan setiap kemungkinan jika akan terjadi kegagalan jasa, dan pihak bank harus membekali setiap karyawannya dengan beberapa alat pemulihan (recovery) yang efektif dan efisien serta berguna untuk memperbaiki kegagalan yang terjadi dalam memberikan kepuasan terhadap setiap nasabahnya [8]. Komitmen suatu bank adalah hal yang sangat penting dalam mendengar dan merespon suara dari para nasabahnya. Yang sangat diharapkan dari kesungguhan upaya itu adalah akan tumbuh sebuah kepercayaan dari para nasabah dalam kejujuran, integritas, dan keandalannya. Sebuah kepercayaan atau trust tersebut adalah sebuah cerminan dari rasa aman pada diri para nasabah karena bank akan yakin bahwa produk atau jasa bank yang dipilih akan memenuhi harapan dari semua nasabahnya [9]. Setiap bank tidak dapat lagi mengambil risiko kehilangan sejumlah nasabahnya, karena ketidakpuasan nasabahnya diabaikan oleh pihak bank. Bank lebih baik mengorbankan uang yang relatif sedikit untuk ganti rugi atau mengkompensasikan rasa kekecewaan dari nasabah tersebut melalui program service recovery [10]. Secara umum service recovery dapat diwujudkan dengan tiga cara pokok yaitu distributive justice, procedural justice dan international justice [11]. Service Recovery sangat efektif untuk kemajuan teknologi dan informasi di sebuah bank karena dapat memberikan kemudahan dalam menjaga dan menjamin keamanan 
dalam bertransaksi dengan itu penulis sangat tertarik untuk mengangkat judul ini karena setiap bank pernah mengalami error atau kegagalan sistem.

Berdasarkan pengamatan yang dilakukan maka penulis menemukan masalah jaringan yang sering berada dalam keadaan pemulihan (offline) sehingga nasabah komplain dengan hal tersebut di Bank BRI Cabang Pasar Horas. Bank BRI Cabang Pasar Horas adalah bank yang terletak dipusat perbelanjaan dengan nasabah yang sangat ramai pengunjung tiap harinya dengan keadaan jaringan yang sering bermasalah maka sangat banyak nasabah yang kecewa kepada Bank BRI bahkan banyak nasabah yang komplain. Hal tersebut terjadi karena ada kerusakan server dari pusat yang berpengaruh ke Bank BRI Cabang Pasar Horas, Dengan masalah yang (sering terjadi) maka penulis tertarik melakukan penelitian lebih dalam untuk dibahas lebih lanjut. Tujuan dari penelitian ini adalah untuk melihat pengaruh kualitas pelayanan terhadap kepuasa nasabah dimana indikator dari kualitas pelayanan tersebut adalah service recovery.

\section{METODE PENELITIAN}

Metode yang digunakan dalam penelitian ini adalah metode kuantitatif yaitu, pendekatan kuantitatif karena data yang disajikan berhubungan dengan angka (kuantitatif). Populasi dari penelitian ini adalah seluruh nasabah pada Bank BRI Unit Pasar Horas yang berjumlah 6.812 orang dengan teknik pengambilan sampel teknik probability sampling yaitu proportionate stratified random sampling dengan menggunakan rumus slovin. Untuk memperoleh data yang jelas dan akurat, maka peneliti mengambil data dari berbagai sumber yang mendukung dalam penelitian tugas akhir dengan menggunakan dua jenis data yaitu : Data Primer dan sekunder. Teknik pengumpulan data yang digunakan penulis untuk mendapatkan data-data yang sesuai dengan tujuan penelitian adalah Observasi yaitu metode penelitian dimana peneliti melakukan pengamatan secara langsung pada obyek penelitian di Bank BRI Unit Pasar Horas serta Kuisioner. Kuesioner adalah instrument atau alat perantara berupa pertanyaan dari peneliti yang biasanya ditujukan kepada responden untuk dijawab. Angket yang berisi kuesioner dan dengan menggunakan tes inteligensi.

Defenisi operasional dari variabel Kualitas Pelayanan (X) adalah Melalui Service Recovery, yaitu kegiatan diperuntukkan atau ditujukan kepada pihak nasabah melalui pelayanan yang dapat memenuhi kebutuhan nasabah. Indikatornya adalah Distributive Justice Pelayanan di Bank BRI Unit Pasar Horas memberikan kompensasi atau ganti rugi kepada nasabah yang sudah kecewa Procedural justice Pelayanan yang dilakukan oleh Bank BRI Unit Pasar Horas cepat serta mempermudah akses dalam menyampaikan keluhan dan saran International justice Sikap dari pihak Bank BRI Unit Pasar Horas terhadap pelanggan apabila terjadi kesalahan teknis (error).

Variabel Kepuasan Nasabah (Y) Melalui Service Recovery adalah Suatu keadaan emosional yang dapat berupa perasaan senang maupun kecewa yang muncul ketika system perbankan error dan disebut rusak, kinerja service recovery yang diinginkan terhadap kinerja hasil yang diharapkan. Indikatornya adalah Attributes related to service (Service Pelayanan masalah dapat dilakukan secara tuntas dan selalu ada jalan keluar sehingga membuat nasabah puas), Attributes related to purchase (Service yang diberikan oleh bank sangat akurat dan ada peluang bagi 
nasabah untuk kembali menggunakan produk dan jasa di Bank BRI Unit Pasar Horas). Instrumen dalam penelitian ini adalah kuesioner. Kuesioner dalam hal ini ditujukan kepada nasabah bank BRI Unit Pasar Horas yang merupakan populasi dan sampel dalam penelitian ini. Dalam penelitian ini, kualitas pelayanan yang merupakan variabel $\mathrm{X}$ mempunyai tiga indikator yaitu distributive justice, procedural justice dan international justice. Ketiga indikator inilah yang membuat penelitian ini berbeda dengan penelitian-penelitian sebelumnya.

Untuk memudahkan penulis dalam mengumpulkan atau menggali data yang berkaitan dengan pelayanan Service Recovery terhadap kepuasan nasabah Bank BRI Unit Pasar Horas, penulis terlebih dahulu merumuskan indikator dari masing-masing variabel. Sebelum penulis melakukan pengolahan data lebih lanjut, data kuesioner lebih daulu diuji validitas dan realibilitas Penelitian ini melakukan uji validasi dan reabilitas terhadap instrumen penelitian dengan menggunakan SPSS dalam penelitian ini peneliti menggunakan skala linkert sebagai alat ukur.

Uji Hipotesis dilakukan dengan melakukan Uji Koefisien Determinasi untuk melihat hubungan atau korelasi antar variabel serta Uji Regresi Linear untuk melihat tingkat signifikansi $\mathrm{X}$ terhadap Y. Analisis regresi ini digunakan untuk mengetahui pengaruh dari variabel bebas (Dependent) yaitu Kualitas Pelayanan terhadap variabel terkait (Independent) yaitu Kepuasan Pelanggan.

Model persamaan regresi linear sederhana adalah seperti berikut ini :

$$
\mathrm{Y}=\mathrm{a}+\mathrm{bX}
$$

Dimana : $\mathrm{Y}=$ Variabel Response

atau Variabel Akibat (Defendent) $\mathrm{X}=$ Variabel Predictor atau Variabel Faktor Penyebab (Independent) $a=$ Konstanta $\quad b=$ Koefisien regresi (Kemiringan);besaran Response yang ditimbulkan oleh Predictor Uji t Uji t digunakan untuk menentukan tingkat signifikan secara parsial antara masingmasing variabel bebas dengan variabel terikat, maka hipotesis harus diuji t pada taraf signifikan sebesar a $=5 \%$ secara dua arah. Jika nilai signifikansi pengujian > 0.05 (pada taraf 5\%), maka H0 diterima dan Ha ditolak, sehingga hipotesis yang dirumuskan tidak terbukti kebenarannya. Jika nilai signifikansi pengujian $<0.05$ (pada taraf 5\%), maka Ho ditolak dan Ha diterima, sehingga hipotesis yang dirumuskan terbukti kebenarannya.

\section{HASIL DAN PEMBAHASAN}

Rekapitulasi jawaban responden

Tabel 1. Rekapitulasi jawaban responden terhadap variable kualitas

\begin{tabular}{|c|c|c|c|c|c|c|}
\hline \multirow{2}{*}{$\begin{array}{l}\text { Pertan } \\
\text { yaan }\end{array}$} & \multicolumn{6}{|c|}{ Pelayanan } \\
\hline & & & kala Lik & & & Jumlah \\
\hline & $\begin{array}{l}\text { Sangat } \\
\text { Setuiu }\end{array}$ & Setuju & $\begin{array}{l}\text { Ragu- } \\
\text { ragu }\end{array}$ & $\begin{array}{l}\text { Kurang } \\
\text { Setuiu }\end{array}$ & $\begin{array}{l}\text { Tidak } \\
\text { Setuiu }\end{array}$ & Jumlah \\
\hline 1. & 43 & 41 & 12 & 3 & 0 & 99 \\
\hline 2. & 29 & 40 & 26 & 4 & 0 & 99 \\
\hline 3. & 35 & 46 & 13 & 5 & 0 & 99 \\
\hline 4. & 36 & 41 & 15 & 7 & 0 & 99 \\
\hline 5. & 32 & 45 & 17 & 5 & 0 & 99 \\
\hline
\end{tabular}

Tabel 2. Rekapitulasi jawaban responden terhadap variable kepuasan nasabah 


\begin{tabular}{crrrrrr}
\hline $\begin{array}{l}\text { Pertan } \\
\text { yaan }\end{array}$ & \multicolumn{3}{c}{ Skala Likert } & & $\begin{array}{l}\text { Jumlah } \\
\text { Responden }\end{array}$ \\
\hline & $\begin{array}{l}\text { Sangat } \\
\text { Setuju }\end{array}$ & Setuju & $\begin{array}{l}\text { Ragu- } \\
\text { ragu }\end{array}$ & $\begin{array}{l}\text { Kurang } \\
\text { Setuju }\end{array}$ & $\begin{array}{l}\text { Tidak } \\
\text { Setuju }\end{array}$ & Jumlah \\
1. & 39 & 38 & 19 & 3 & 0 & 99 \\
2. & 23 & 42 & 30 & 4 & 0 & 99 \\
3. & 37 & 47 & 10 & 5 & 0 & 99 \\
4. & 34 & 44 & 14 & 7 & 0 & 99 \\
5. & 40 & 38 & 16 & 5 & 0 & 99 \\
\hline
\end{tabular}

Sumber :Diolah Sendiri

Dari tabel 1 dan 2 diatas dapat kita lihat bahwa jawaban responden variable kualitas pelayanan dan kepuasan nasabah lebih dominan setuju dan sangat setuju. Hal ini menunjukan bahwa kualitas pelayanan service recovery di Bank BRI Cabang Pematangsiantar Unit Pasar Horas sangat Baik pelayanannya berdampak positif terhadap kepuasan nasabah.

Hasil rekapitulasi jawaban responden di atas di peroleh dari kuesioner 99 responden yang benarbenar disebarkan kepada nasabah Bank BRI Cabang Pematangsiantar Unit Pasar Horas dan kuesioner 99 responden $100 \%$ kembali. Selain kuesioner peneliti juga melakukan observasi langsung ke Bank BRI Cabang Pematangsiantar Unit Pasar Horas selama 2 minggu dan juga melakukan wawancara kepada beberapa nasabah.

Yang menjadi persoalan umum pada Bank BRI Cabang Pematangsiantar Unit Pasar Horas adalah masyarakat atau nasabah kurang memahami arti dari service recoveryyang sebenarnya karena data tersebut banyak orang tua dan ibuibu yang tidak fasih terhadap bahasa indonesia sehingga terjadi kesalah pahaman antara nasabah dan juga service recovery.

Untuk menentukan kedudukan variabel pelayanan prima (X) dan kepuasan nasabah (Y) menggunakan langkah-langkah berikut ini :

1. Mencari jumlah skor hasil kuesioner dengan cara sebagai berikut :

Total Skor $=($ jumlah responden yang menjawab sangat setuju $x$ 5) + (jumlah responden yeng menjawab setuju $\mathrm{x} 4)+$ (jumlah responden yang menjawab raguragu $\mathrm{x} 3)+($ jumlah respondden yang menjawab tidak setuju x 2) + (jumlah responden yang menjawab sangat tidak setuju x 1).

2. Membuat daerah kategori kontinum menjadi lima tingkatan yaitu sangat tidak baik, tidak baik, cukup baik, baik, dan sangat baik dengan langkahlangkah sebagai berikut :

a. Menentukan kontinum tertinggi dan terendah

Tertinggi $=$ skor tertinggi $\mathrm{x}$ jumlah pernyataan $\mathrm{x}$ jumlah responden

Terendah $=$ skor terndah $\mathrm{x}$ jumlah pernyataan $\mathrm{x}$ jumlah responden

b. Menetukan selisih skor kontinum dari setiap tingkatan dengan rumus sebagai berikut :

NJI (Nilai Jenjang Interval) = Nlai Tertiinggi-Nilai Terendah

Jumlah Kriteria Pernnyataan

c. Menentukan daerah kontinum dengan cara menambahkan selisih NJI dan menentukan daerah letak skor hasil penelitian sebagai berikut : 
Gambar 1. Garis Kontinum

\begin{tabular}{|l|l|l|l|l|} 
Sangat Tidak Baik & Tidak Baik & Cukup Baik & Baik & Sangat Baik \\
\hline & & & & \\
& & & \\
Sumber : Sugiyono (2012)
\end{tabular}

1. Menentukan persentase letak skor hasil penelitian (rating scale) dalam garis kontinum dengan rumus sebagai berikut :

Persentase skor $=($ Skor Aktual $/$ Skor Ideal) x $100 \%$
Skor aktual adalah jawaban seluruh responden atas angket yang telah diajukan.

Skor ideal adalah skor tertinggi

1. Kualitas Pelayanan

Tabel 3. Rekapitulasi \% jawaban responden terhadap variable kualitas Pelayanan

\begin{tabular}{ccccccccc}
\hline $\begin{array}{l}\text { Pertan } \\
\text { yaan }\end{array}$ & \multicolumn{3}{c}{ Skala Likert } & & $\begin{array}{l}\text { Jumlah } \\
\text { Responden }\end{array}$ & $\begin{array}{c}\text { Skor } \\
\text { Total }\end{array}$ \\
\hline & Sangat & Setuju & Ragu- & Kurang & Tidak & Jumlah & $(\%)$ & Skor \\
& Setuju & & ragu & Setuju & Setuju & & & Ideal \\
1. & 43 & 41 & 12 & 3 & 0 & 99 & 421 & 495 \\
& $43,4 \%$ & $41,4 \%$ & $12,1 \%$ & $3,0 \%$ & $0,0 \%$ & $100 \%$ & $85 \%$ & \\
2. & 29 & 40 & 26 & 4 & 0 & 99 & 391 & 495 \\
& $29,2 \%$ & $40,4 \%$ & $26,2 \%$ & $4,0 \%$ & $0,0 \%$ & $100 \%$ & $78 \%$ & \\
3. & 35 & 46 & 13 & 5 & 0 & 99 & 408 & 495 \\
& $35,3 \%$ & $46,4 \%$ & $13,1 \%$ & $5,0 \%$ & $0,0 \%$ & $100 \%$ & $82 \%$ & \\
4. & 36 & 41 & 15 & 7 & 0 & 99 & 404 & 495 \\
& $36,3 \%$ & $41,4 \%$ & $15,1 \%$ & $7,0 \%$ & $0,0 \%$ & $100 \%$ & $81 \%$ & \\
5. & 32 & 45 & 17 & 5 & 0 & 99 & 401 & 495 \\
& $32,3 \%$ & $45,4 \%$ & $17,1 \%$ & $5,0 \%$ & $0,0 \%$ & $100 \%$ & $81 \%$ & \\
& & & Skor Aktual & & & 2025 & \\
\hline
\end{tabular}

Sumber : Diolah Sendiri

Dimasukan dalam garis kontinum, yang pengukurannya ditentukan dengan cara sebagai berikut :

Nilai indeks maksimum $=5 \times 5 \times 99=$ 2475

Nilai indeks minimum $=1 \times 5 \times 99=$ 495

$\mathrm{Nji}=$ (nilai maksimum - nilai minimum) $: 5$

$$
\begin{aligned}
& =(2475-495): 5 \\
& =396
\end{aligned}
$$

Presentase Skor $=\underline{\text { Skor aktual }} \times 100 \%$

Skor ideal

$$
\begin{aligned}
& =(2025: 2475) \times 100 \% \\
& =82 \%
\end{aligned}
$$

Keterangan mengenai batas kontinum dapat kita lihat seperti dibawah ini

1) $495 \leq$ skor 891 berada dalam kategori sangat tidak baik

2) 891 < skor 1,287 berada dalam kategori tidak baik 
3) 1,287 skor 1,683 berada dalam kategori cukup baik

4) 1,683 skor 2,079 berada dalam kategori baik
5) 2,079 <skor 2,475 berada dalam kategori sangat baik

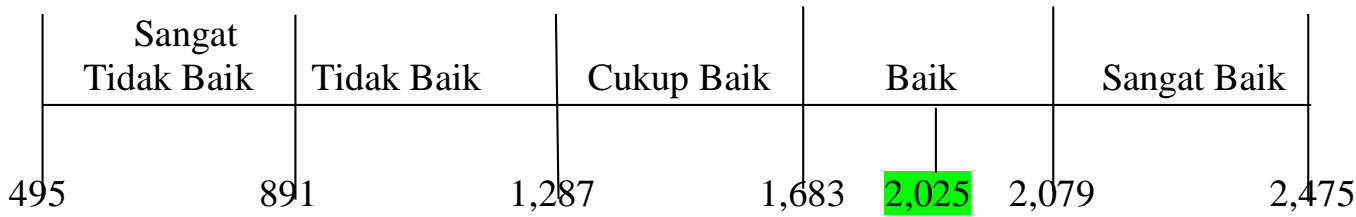

Gambar 2. Garis Kontinum Kualitas Pelayanan (X)

Berdasarkan gambar 2 diatas dapat diketahui bahwa sacara keseluruhan persepsi responden tentang kualitas pelayanan sebesar 2025 atau $82 \%$. Hal ini menunjukan bahwa sebagian besar responden menyatakan kualitas pelayanan pada Bank BRI Cabang Pematangsiantar Unit Pasar Horas baik.

2. Kepuasan Nasabah

Tabel 4. Rekapitulasi \% jawaban responden terhadap variable Kepuasan Nasabah

\begin{tabular}{|c|c|c|c|c|c|c|c|c|}
\hline \multirow[t]{2}{*}{$\begin{array}{l}\text { Pertan } \\
\text { yaan }\end{array}$} & \multicolumn{5}{|c|}{ Skala Likert } & \multirow{2}{*}{$\begin{array}{l}\text { Jumlah } \\
\text { Responden } \\
\text { Jumlah }\end{array}$} & \multirow{2}{*}{$\begin{array}{l}\text { Skor } \\
\text { Total } \\
(\%)\end{array}$} & \\
\hline & $\begin{array}{l}\text { Sangat } \\
\text { Setuju }\end{array}$ & Setuju & $\begin{array}{l}\text { Ragu- } \\
\text { ragu }\end{array}$ & $\begin{array}{l}\text { Kurang } \\
\text { Setuju }\end{array}$ & $\begin{array}{l}\text { Tidak } \\
\text { Setuju }\end{array}$ & & & $\begin{array}{l}\text { Skor } \\
\text { Ideal }\end{array}$ \\
\hline 1. & $\begin{array}{c}39 \\
39,3 \%\end{array}$ & $\begin{array}{c}38 \\
38,3 \%\end{array}$ & $\begin{array}{c}19 \\
19,1 \%\end{array}$ & $\begin{array}{c}3 \\
3,0 \%\end{array}$ & $\begin{array}{c}0 \\
0,0 \%\end{array}$ & $\begin{array}{c}99 \\
100 \%\end{array}$ & $\begin{array}{l}410 \\
82 \%\end{array}$ & 495 \\
\hline 2. & $\begin{array}{c}23 \\
23,2 \%\end{array}$ & $\begin{array}{c}42 \\
42,4 \%\end{array}$ & $\begin{array}{c}30 \\
30,3 \%\end{array}$ & $\begin{array}{c}4 \\
4,0 \%\end{array}$ & $\begin{array}{c}0 \\
0,0 \%\end{array}$ & $\begin{array}{c}99 \\
100 \%\end{array}$ & $\begin{array}{c}381 \\
76 \%\end{array}$ & 495 \\
\hline 3. & $\begin{array}{c}37 \\
37,3 \%\end{array}$ & $\begin{array}{c}47 \\
47,4 \%\end{array}$ & $\begin{array}{c}10 \\
10,1 \%\end{array}$ & $\begin{array}{c}5 \\
5,0 \%\end{array}$ & $\begin{array}{c}0 \\
0,0 \%\end{array}$ & $\begin{array}{c}99 \\
100 \%\end{array}$ & $\begin{array}{l}413 \\
83 \%\end{array}$ & 495 \\
\hline 4. & $\begin{array}{c}34 \\
34,3 \%\end{array}$ & $\begin{array}{c}44 \\
44,4 \%\end{array}$ & $\begin{array}{c}14 \\
14,1 \%\end{array}$ & $\begin{array}{c}7 \\
7,0 \%\end{array}$ & $\begin{array}{c}0 \\
0,0 \%\end{array}$ & $\begin{array}{c}99 \\
100 \%\end{array}$ & $\begin{array}{l}402 \\
81 \%\end{array}$ & 495 \\
\hline 5. & $\begin{array}{c}40 \\
40,4 \%\end{array}$ & $\begin{array}{c}38 \\
38,3 \%\end{array}$ & $\begin{array}{c}16 \\
16,1 \%\end{array}$ & $\begin{array}{c}5 \\
5,0 \%\end{array}$ & $\begin{array}{c}0 \\
0,0 \%\end{array}$ & $\begin{array}{c}99 \\
100 \%\end{array}$ & $\begin{array}{l}410 \\
82 \%\end{array}$ & 495 \\
\hline & & & Skor $A$ & tual & & & & \\
\hline
\end{tabular}

Sumber : Diolah Sendiri

Dimasukan dalam garis kontinum, yang pengukurannya ditentukan dengan cara sebagai berikut :

Nilai indeks maksimum $=5 \times 5 \times 99=$ 2475

$$
\begin{aligned}
& =(2475-495): 5 \\
& =396
\end{aligned}
$$

Presentase Skor $=\underline{\text { Skor aktual }} \times 100 \%$
Nilai indeks minimum $=1 \times 5 \times 99=$ 495

$\mathrm{Nji}=$ (nilai maksimum - nilai minimum) $: 5$

\section{Skor ideal}

$=(2016: 2475) \times 100 \%$

$=81,5 \%$ 
Keterangan mengenai batas kontinum dapat kita lihat seperti dibawah ini

1) 495 skor 891 berada dalam kategori sangat tidak baik

2) $891 \leq$ skor 1,287 berada dalam kategori tidak baik
3) 1,287 < skor 1,683 berada dalam kategori cukup baik

4) 1,683 skor 2,079 berada dalam kategori baik

5) 2,079 skor 2,475 berada dalam kategori sangat baik

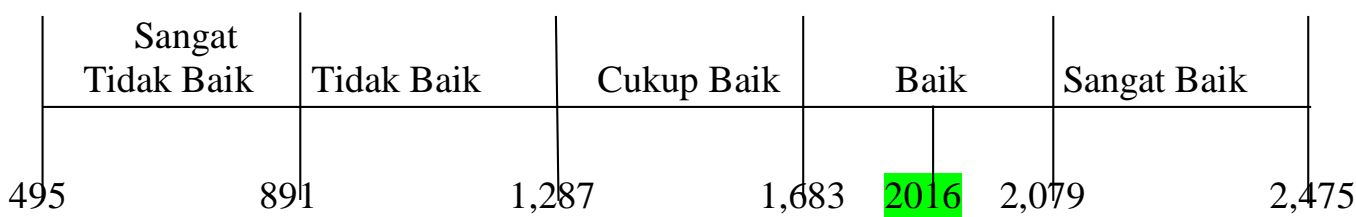

Gambar 3. Garis Kontinum Kepuasan Nasabah (Y)

Berdasarkan gambar 3 diatas dapat diketahui bahwa secara keseluruhan persepsi responden tentang kualitas pelayanan sebesar 2016 atau $81,5 \%$. Hal ini menunjukan bahwa sebagian besar responden menyatakan kepuasan nasabah pada BRI Cabang Pematangsiantar Unit Pasar Unit Pasar Horas baik.

\section{Uji Hipotesis}

Koefisien Determinasi $\left(\mathbf{R}^{2}\right)$

Uji koefisien determinasi digunakan untuk mengetahui persentase sumbangan pengaruh variable kualitas pelayanan terhadap variable kepuasaan nasabah.

Tabel 5. Hasil Uji Koefisien Determinasi

Model Summary ${ }^{\mathrm{b}}$

\begin{tabular}{|c|c|c|c|c|c|c|c|c|c|}
\hline Model & $\mathrm{R}$ & $\begin{array}{c}\mathrm{R} \\
\text { Square }\end{array}$ & $\begin{array}{l}\text { Adjuste } \\
\text { d R } \\
\text { Square }\end{array}$ & $\begin{array}{l}\text { Std. Error } \\
\text { of the } \\
\text { Estimate }\end{array}$ & $\begin{array}{c}\mathrm{R} \\
\text { Square } \\
\text { Change }\end{array}$ & F Change & df1 & df 2 & $\begin{array}{l}\text { Sig. F } \\
\text { Change }\end{array}$ \\
\hline 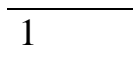 & .879 & .772 & .770 & 1.278 & .772 & 328.644 & & 97 & .000 \\
\hline
\end{tabular}

a. Predictors: (Constant), $\mathrm{x}$

b. Kepuasan Nasabah : y

Sumber data primer yang diolah SPSS

Dari output model summary, diketahui nilai koefisien determinasi $(\mathrm{R}$ Square) sebesar 0,772. Besarnya angka koefisien determinasi 0,772 sama dengan $77,2 \%$, amgka tersebut mengandung arti bahwa kualitas pelayanan mempengaruhi kepuasan nasabah, sedangkan sisanya $23,8 \%$ dipengaruhi oleh variable lain yang tidak di bahas dalam penelitian ini.
Semakin kecil nilai koefisien determinasi (R Square), maka ini artinya pengaruh variable bebas terhadap variable terikat semakin lemah. Sebaliknya jika R Square semakin mendekati 1, maka pengaruh tersebut akan semakin kuat. 
Uji t atau parsial pada dasarnya digunakan untuk menunjukan pengaruh satu variable independen secara individual dalam menerangkan variable dependen. Besarnya angka t tabel dengan ketentuan sig.0,05 dan jumlah responden sebesar 99 sehingga diperoleh ketentuan nilai t tabel sebesar 1,984.
1). Jika nilai signifikan pengujian $>0,05$ maka tidak ada pengaruh secara parsial, maka Ho diterima dan $\mathrm{Ha}$ ditolak

2). Jika nilai signifikan pengujian $<0,05$ ada pengaruh secara parsial, maka Ho ditolak dan $\mathrm{Ha}$ diterima, sehingga hipotesis yang dirumuskan terbukti kebenarannya.

Tabel 6. Hasil Uji Regresi

Coefficients $^{\mathrm{a}}$

\begin{tabular}{llrrrrr}
\hline & & \multicolumn{2}{c}{$\begin{array}{c}\text { Unstandardized } \\
\text { Coefficients }\end{array}$} & \multicolumn{2}{c}{$\begin{array}{c}\text { Standardized } \\
\text { Coefficients }\end{array}$} & \\
Model & & \multicolumn{1}{c}{ B } & Std. Error & Beta & \multicolumn{1}{c}{ t } & \multicolumn{1}{c}{ Sig. } \\
\hline 1 & (Constant) & 2.262 & 1.007 & & 2.247 & .027 \\
& Kualitas Pelayanan & .885 & .049 & .879 & 18.129 & .000 \\
\hline
\end{tabular}

a. Dependent Variable: y

Sumber data primer yang diolah SPSS

Dari hasil output diperoleh nilai $\mathrm{t}$ hitung sebesar 18.129 sedangkan nilai t tabel sebesar 1,984. Maka dapat diketahui t hitung $(18,129)>\mathrm{t}$ tabel $(1,984)$ dengan tingkat signifikan $0,000<$ 0,027 . Sehingga dapat disimpulkan bahwa Ha diterima yang artinya kualitas pelayanan berpengaruh positif signifikan terhadap kepuasan nasabah pada Bank BRI Cabang Pematangsiantar Unit Pasar Horas. Hasil penelitian ini sama dengan hasil penelitian yang dilakukan oleh I Wayan Sujana [12] yang mengatakan bahwa kualitas pelayanan berpengaruh kepada kepuasan nasabah. Hasil yang sama juga dikemukan oleh Murdifin [13].

Untuk mencapai kepuasan nasabah yang diharapkan maka tentu suatu perusahaan lebih mengedepankan kualitas pelayanan yang diberikan kepada nasabah. Untuk itu diharapkan indikator dari kualitas pelayanan yakni distributive justice, Procedural justice, International justice. Mampu menghasilkan kualitas pelayanan yang handal serta berkopeten untuk melayani nasabah secara spesifik.

Semakin tinggi kualitas pelayanan yang diberikan maka akan semakin tinggi pula kepuasan nasabah yang diperoleh. Ukuran kualitas pelayanan bukan hanya ditentukan oleh pihak yang melayani saja, tetapi lebih banyak ditentukan oleh pihak yang dilayani karena mereka yang menikmati layanan sehingga dapat mengukur kualitas pelayanan berdasarkan harapan-harapan mereka berdasarkan kepuasannya.

\section{KESIMPULAN}

adalah :

Kesimpulan dari penelitian ini

1. Dari hasil pengolahan SPSS diperoleh nilai t hitung sebesar 18.129 sedangkan nilai t tabel sebesar 1,984. Maka dapat diketahui $\mathrm{t}$ hitung $(18,129)>\mathrm{t}$ tabel $(1,984)$ dengan tingkat signifikan $0,000<$ 0,027 . Sehingga dapat disimpulkan bahwa Ha diterima yang artinya kualitas pelayanan berpengaruh positif signifikan terhadap kepuasan nasabah pada Bank BRI Cabang Pematangsiantar Unit Pasar Horas.

2. Dari hasil deskripsi responsen dimana penilaian terhadap kualitas pelayanan nasabah secara keseluruhan sudah 
dianggap Baik berada di score 2,025 dan penilaian terhadap kepuasan pelayanan nasabah sudah dianggap baik berada di score 2.016. Terdapat pengaruh yang positif signifikan antara Kualitas Pelayanan terhadap Kepuasan Nasabah pada Bank BRI Cabang Pematangsiantar Unit Pasar Horas, kontribusi pengaruh variabel kualitas pelayanan service recovery terhadap kepuasan nasabah sebesar $77,2 \%$ dan selebihnya 22,8 dipengaruhi oleh faktor yang lain yang tidak diteliti dalam penelitian ini.

\section{REFERENSI}

[1] S. Nawangsari and R. Widiastuti, "Analisis Pengaruh Kualitas Layanan, Kepercayaan dan Layanan Mobile Banking terhadap Kepuasan Nasabah Bank (Studi Kasus pada PT Bank DKI-Depok)," Sebatik, vol. 22, no. 2, pp. 51-55, 2018.

[2] S. M. Janosik, "Pengaruh Kualitas Pelayanan Terhadap Loyalitas Melalui Kepuasan Nasabah Tabungan Sebagai Variabel Intervening Pada PT. Bank Negara Indonesia Tbk, Cabang Malang (Studi Pada Nasabah PT. Bank Negara Indonesia Tbk, Cabang Malang)," NASPA J., vol. 42, no. 4, p. 1, 2020.

[3] N. Nurdin, I. Musyawarah, N. Nurfitriani, and A. Jalil, "Pengaruh Pelayanan Mobile Banking Terhadap Kepuasan Nasabah (Studi Pada Mahasiswa Perbankan Syariah IAIN Palu)," J. Ilmu Perbank. dan Keuang. Syariah, vol. 2, no. 1, pp. 87-104, 2020.

[4] T. Trimulato, "AKSELERASI TINGKAT PENGETAHUAN MAHASISWA TENTANG SISTEM DAN PRODUK PERBANKAN SYARIAH MELALUI MEDIA ONLINE PADA PROGRAM STUDI
PERBANKAN SYARIAH UIN ALAUDDIN MAKASAR," Ekspansi J. Ekon. Keuangan, Perbankan, dan Akunt., vol. 12, no. 1, pp. 12-30, 2020.

[5] S. B. Fatimah and A. Hendratmi, "Digitalisasi Pada Bank Mandiri Syariah Di Tengah Persaingan Dan Perubahan Teknologi," $J$. Ekon. Syariah Teor. dan Terap., vol. 7, no. 4, pp. 795-813, 2020.

[6] R. Zulkarnain, H. E. R. Taufik, and A. D. Ramdansyah, "Pengaruh Kualitas Pelayanan Dan Kualitas Produk Terhadap Loyalitas Nasabah Dengan Kepuasan Nasabah Sebagai Variabel Intervening (Studi Kasus Pada PT Bank Syariah Mu'amalah Cilegon)," J. Manaj. Dan Bisnis, vol. 2, no. 01, pp. 87110, 2020.

[7] D. Suryadi, "SERVICE QUALITY IN CASE: KEGAGALAN LAYANAN (SERVICE FAILURE) PERBANKAN SYARIAH DAN STRATEGI PEMULIHAN LAYANAN (SERVICE RECOVERY)," $J . \quad$ AsySyukriyyah, vol. 21, no. 1, pp. 83105, 2020.

[8] S. Himmah, "PENGARUH SERVICE RECOVERY TERHADAP LOYALITAS

\section{KONSUMEN MELALUI}

KEPUASAN KONSUMEN

SEBAGAI VARIABEL

INTERVENING (Studi pada

Nasabah Bank BRI Cabang Malang)," J. Ilmu Manaj., vol. 4, no. 2, pp. 210-222, 2020.

[9] S. Randi, T. Mery, and J. Purbo, "Pengaruh kualitas pelayanan, kepercayaan dan nilai nasabah terhadap kepuasan nasabah," Universitas Bung Hatta, 2020.

[10] D. Aprilia, "Implementsi Service Recovery Pelayanan Oleh Customer Service Untuk 
Meningkatkan Kepuasan Nasabah Pada Bank Syariah Mandiri Kantor Cabang Teluk Betung," IAIN Metro, 2020.

[11] M. Tansi, I. Agustin, and S. Wijaya, "PENGARUH PEMULIHAN JASA TERHADAP KEPUASAN DAN KEPERCAYAAN

PELANGGAN ATAS MEREK HOTEL: STUDI PADA HOTEL BERBINTANG SATU SAMPAI TIGA DI INDONESIA," $J$. Manaj. Perhotelan, vol. 6, no. 2, pp. 99-110, 2020.
[12] I. W. Sujana, "Pengaruh Kualitas Pelayanan terhadap Kepuasan Nasabah pada Bank Syariah di Kota BauBau," J. Ilm. Manaj. Emor (Ekonomi Manaj. Orientasi Riset), vol. 3, no. 2, pp. 187-199, 2020.

[13] I. Murdifin, "Pengaruh Kualitas Pelayanan Terhadap Kepuasan Nasabah Pada PT. Bank Danamon Cabang Makassar," Celeb. Equilibrum J., vol. 1, no. 2, pp. 23-33, 2020. 